\title{
The Effectiveness of Pretreatment Methods on COD and Ammonia Removal from Landfill Leachate
}

\author{
M. Poveda, Q. Yuan, and J. Oleszkiewicz
}

\begin{abstract}
The goal of this experiment is to evaluate the effectiveness of different leachate pre-treatment options in terms of COD and ammonia removal. This research focused on the evaluation of physical-chemical methods for pre-treatment of leachate that would be effective and rapid in order to satisfy the requirements of the sewer discharge by-laws. The four pre-treatment options evaluated were: air stripping, chemical coagulation, electro-coagulation and advanced oxidation with sodium ferrate. Chemical coagulation reported the best COD removal rate at $43 \%$, compared to $18 \%$ for both air stripping and electro-coagulation, and $20 \%$ for oxidation with sodium ferrate. On the other hand, air stripping was far superior to the other treatment options in terms of ammonia removal with $86 \%$. Oxidation with sodium ferrate reached only $16 \%$, while chemical coagulation and electro-coagulation removed less than $10 \%$. When combined, air stripping and chemical coagulation removed up to $50 \%$ COD and $85 \%$ ammonia.
\end{abstract}

Index Terms - Leachate pretreatment, air stripping, chemical coagulation, electro-coagulation, oxidation.

\section{INTRODUCTION}

Landfillleachate is produced by the seeping of liquids through landfilled waste. Rain water or melted snow percolating into the waste, as well as the original water content or humidity of the waste itself and the degradation and compaction of the organic fraction, all contribute to the generation of leachate [1], [2]. The characteristics of the leachate are closely related to the conditions on the disposal site and the degradation time that has passed (i.e. landfill age). In addition, the parameters that affect the leachate characteristics include precipitation, surface run-off, infiltration, evapotranspiration, type of waste, and water content of waste etc. Kjeldsen et al. [1] introduced four major groups that would represent the typical Municipal Solid Waste (MSW) Landfill leachate parameters: 1) Organic matter: both biodegradable and non-biodegradable measured as COD, $\mathrm{BOD}_{5}$ or Total Organic Carbon (TOC); 2) Inorganic compounds: nitrogen (measured as ammonia and Total Nitrogen), calcium, magnesium, sodium, potassium, iron, manganese, chloride, sulfate and hydrogen carbonate; 3) Heavy metals, and 4) Xenobiotic organic compounds (XOC's). The concentrations of these compounds in leachate, especially COD and Ammonia, are significantly higher that typical municipal wastewater. They would have a negative

Manuscript received March 22, 2015; revised June 17, 2015.

Q. Yuan and J. Oleszkiewicz are with the Department of Civil Engineering, University of Manitoba, Winnipeg, Canada, MB R3T 5V6 (e-mail: qiuyan.yuan@umanitoba.ca, jan.oleszkiewicz@umanitoba.ca).

M. Poveda is with University of Manitoba, Canada (e-mail: mariopq@gmail.com). impact on the wastewater treatment process and decrease the effluent quality. Therefore, pre-treating the leachate on site before it is discharged into the sewer system and mixed with the municipal wastewater would be beneficial for the subsequent biological treatment in the wastewater treatment plant.

Physico-chemical treatment of leachate is the most common practice, with processes such as flotation, adsorption, precipitation, $\mathrm{pH}$ adjustment, filtration, oxidation being used as pretreatment before further biological degradation or as a final step to improve the final effluent characteristics [2], [3]. The pretreatment options selected for this research were: air stripping which focus on the removal of ammonia, chemical coagulation and electro-coagulation which target the removal of colloidal particles in order to reduce the chemical oxygen demand (COD) and advanced oxidation with sodium ferrate to provide a complete degradation of organic contaminants.

Air stripping is the most common procedure used to lower high concentrations of ammonia in landfill leachate, with reported ammonia removal rates of around 95\% [4]-[6]. It involves the mass transfer of a gas from the liquid phase to the gas phase by increasing the contact surface area available between the liquid and another gas which has a much lower concentration of the gas to be removed [7]. The procedure typically employs air to strip ammonia, odorous gases and other volatile compounds. For wastewater applications, the procedure is usually carried by using a trickling filter or stripping tower, where the wastewater is dispersed into a medium to maximize the surface contact area between the liquid and the air.

Chemical coagulation is a simple technique widely used to remove non-biodegradable organic compounds from landfill leachate [8]-[10]. The main idea behind chemical coagulation is to destabilize colloidal particles (around 0.01 to $1 \mu \mathrm{m}$ ) present in wastewater. Adding a coagulant compound neutralizes the electrical charges maintaining the colloids in suspension, then by rapidly mixing the collision of particles increase their size and they can be removed by traditional methods such as settling or filtration [7]. Aluminum sulfate (alum), ferrous sulfate and ferric chloride are among the most commonly used chemical coagulants for leachate. Research by Renou et al., [3], Tatsi et al. [10] and Amokrane et al. [8] found that iron salts produced better results than aluminum salts in terms of turbidity and COD removal in leachate, a claim also supported by the literature review presented in [3] where the expected COD removal rate is in the order of $50-60 \%$. A wide range of "optimum" $\mathrm{pH}$ values for chemical coagulation of leachate using iron salts have been proposed. This can be explained by the various hydrolysed species that $\mathrm{Fe}^{3+}$ can form depending on the sample's $\mathrm{pH}$ (acidic 
conditions: poly-nuclear cations like $\mathrm{Fe}_{2}(\mathrm{OH})_{2}{ }^{4+}$, basic conditions: anions like $\mathrm{Fe}(\mathrm{OH})_{3}[11]$.

Electro-coagulation is a procedure that involves the formation of the coagulant by electrolytic oxidation of a sacrificial electrode, the destabilization of the contaminants and the eventual aggregation into flocs and removal by precipitation and/or filtration methods. The metal ions generated from the sacrificial electrode hydrolyze into polymeric hydroxides, which are excellent coagulation agents [12]. Compared to traditional chemical coagulation, electro-coagulation advantages include less sludge production and avoiding transferring needless compounds into the leachate [13]. Due to the numerous and sensitive parameters governing this technique (electrode material and contact area, type and amount of current, voltage, contact time) its application is not very common for the treatment of landfill leachate. High turbidity and color removal rates are reported, but COD removal rates range from $32 \%$ to $90 \%$ [13], [14].

Advanced oxidation with ferrate (VI) salts has recently been studied for disinfection purposes in wastewater and water treatment [15], [16]. Ferrate salts are very strong chemical oxidants. As they are being reduced, they produce ferric hydroxide which additionally serves as a coagulant agent [17], [18]. Two main compounds usually used are sodium ferrate $\left(\mathrm{Na}_{2} \mathrm{FeO}_{4}\right)$ and potassium ferrate $\left(\mathrm{K}_{2} \mathrm{FeO}_{4}\right)$.

The main goal of this research was to assess the effectiveness of the selected physical-chemical methods for the pretreatment of landfill leachate in terms of ammonia and COD removal. Additionally, the effect of the pre-treated leachate mixing with wastewater at different percentage on the nitrification performance of BNR system was also evaluated.

\section{MATERIALS AND METHODS}

\section{A. Sample Collection and Leachate Characterization}

Two samples were taken from BRRMF on August 2013 (300 L) and February 2014 (100 L), to evaluate the variation in leachate composition between summer and winter. Due to variation of the chemical composition of leachate within the landfill, a sample was collected from two leachate collection wells and mixed in 1:1 ratio to be representative. Based on the historical landfill leachate data, leachate was collected from one well that has highest BOD values, and from the other well that has the highest COD, ammonia and heavy metals concentrations among all the wells in the landfill. High Density Polyethylene (HDPE) carboys were used for collecting leachate. Leachate was filled to the top to reduce headspace in the containers and maintain anaerobic conditions. The samples were stored at $4{ }^{\circ} \mathrm{C}$ to limit biological degradation. The main characteristic of the sampled leachate are presented in Table I.

\section{B. Analytical Methods}

COD, Total Nitrogen (TN) and Total Phosphorus (TP) were measured using $\mathrm{HACH}$ digestion vials. $\mathrm{BOD}_{5}$ and TSS measurements were carried out following laboratory procedures according to the Standard Methods [19]. Dissolved organic carbon (DOC) analyses were performed using the Fusion Total Organic Carbon Analyzer (TELEDYNE TEKMAR). Ammonnia $\left(\mathrm{NH}_{3} \mathrm{~N}\right)$, was measured using an automatic flow injection analyser Quick Chem 8500, LACHAT Instruments.

TABLE I: CHARACTERISTICS OF LEACHATE

\begin{tabular}{lc}
\hline \multicolumn{1}{c}{ Parameter } & Average Value $(\mathrm{mg} / \mathrm{L})$ \\
\hline $\mathrm{pH}$ & $7.2 \pm 0.1$ \\
$\mathrm{COD}$ & $1939 \pm 108$ \\
$\mathrm{TSS}$ & $336 \pm 203$ \\
$\mathrm{BOD}_{5}$ & $248 \pm 20$ \\
$\mathrm{DOC}$ & $450 \pm 105$ \\
$\mathrm{TN}$ & $759 \pm 56$ \\
$\mathrm{NH}_{3}-\mathrm{N}$ & $646 \pm 84$ \\
$\mathrm{TP}$ & $6.7 \pm 1.1$ \\
\hline
\end{tabular}

\section{Leachate Pretreatment}

\section{1) Air stripping}

Clear polyvinyl chloride (PVC) reactors $(20 \mathrm{~cm}$ in diameter and $40 \mathrm{~cm}$ in height) with $4.0 \mathrm{~L}$ working volume were used for evaluating this treatment option. Mixing speed was set at 125 $\mathrm{rpm}$. Two operational conditions were tested: 1) mixing with no air flow; 2) mixing with $1 \mathrm{~L}$ air/L/min. Four $\mathrm{pH}$ conditions were also evaluated: original $\mathrm{pH}$ of the sample (7.0), 10.0, 11.0 and 12.0. The tests were conducted for 48 hours, with samples taken at intervals to determine the best treatment duration. The reactors were operated at room temperature (21 $\pm 2^{\circ} \mathrm{C}$ ).

\section{2) Chemical coagulation}

Chemical coagulation was carried out using Ferric Chloride solution $\left(\mathrm{FeCl}_{3}\right)$. A set of preliminary tests were conducted without $\mathrm{pH}$ adjustment of the sample (approximate $\mathrm{pH}=7.2$ ) with different coagulant dosages to determine the optimal range. Based on the results, a range from 34 to 172 $\mathrm{mg}$ as $\mathrm{Fe} / \mathrm{L}$ (corresponding to a range from 100 to $500 \mathrm{mg}$ $\mathrm{FeCl}_{3} / \mathrm{L}$ ) was determined. Additionally, based on the assumption that colloidal particles are negatively charged, the chemical coagulation tests were carried out under acidic conditions, at an expected optimal value of 5.0.Following the procedure on ASTM D2035-13 [19], a typical Jar test apparatus was then employed to evaluate the coagulant doses at different $\mathrm{pH}$ values: 7.0 (original $\mathrm{pH}$ of the sample), 6.0, 5.0 and 4.0 .

\section{3) Electro-coagulation}

The electro-coagulation tests were conducted using 2 high purity Iron electrodes with an effective surface area of $45 \mathrm{~cm}^{2}$ and a $2.0 \mathrm{~cm}$ gap between them in a $1 \mathrm{~L}$ glass beaker. The following parameters were evaluated: 1) contact time of 5, 15 and 30 minutes, 2) $\mathrm{pH}$ values: original of the sample (7.0), 8.0 and 6.0 and 3) current density: 50, 100, 200 and $300 \mathrm{~A} / \mathrm{m} 2$. Current was supplied by a KEPCO DC power source (Model BOP $100-2 \mathrm{D}, 0$ to $\pm 100 \mathrm{~V}, 0$ to $\pm 2 \mathrm{~A}$ ).

\section{4) Advanced oxidation with sodium ferrate}

Sodium ferrate $\left(\mathrm{Na}_{2} \mathrm{FeO}_{4}\right)$ was produced in the laboratory following a wet oxidation procedure where hypochlorite was used to oxidize an iron salt under a strong alkaline environment [20]. Due to the rapid degradation of this compound, the solution was prepared and used on the same 
day. Ferrate concentration was measured using a UV-Visible Spectrophotometer (Ultrospec 2100 pro, Biochrom Ltd.) at a wavelength of $510 \mathrm{~nm}$. Molar absorption coefficient: 1150 M-1 cm-1, cell path length: $10 \mathrm{~cm}$. The dose range tested in the jar test system was from 50 to $200 \mathrm{mg} \mathrm{Fe} / \mathrm{L}$ in $50 \mathrm{mg}$ increments, and the $\mathrm{pH}$ conditions were the original $\mathrm{pH}$ of the sample (7.4), 6.0, 5.0 and 4.0. For $\mathrm{pH}$ reduction, an $18 \% \mathrm{w} / \mathrm{w}$ solution of $\mathrm{HCl}$ was used. For this test, the additional measurement of dissolved organic carbon (DOC) was introduced to better evaluate the effect on the organic fraction of the leachate.

\section{Combination of Pretreatment Options}

Based on the removal percentages of the two parameters (COD and ammonia) obtained from previous tests, chemical coagulation and air stripping were selected as the best treatment options. These two options were combined under their optimal conditions to further evaluate the removal efficiency:

\section{Combination 1:}

1) Air stripping for 48 hours, air flow of $1 \mathrm{~L} / \mathrm{L} / \mathrm{min}, \mathrm{pH}$ adjusted to 11.0 with $\mathrm{NaOH}$

2) Chemical coagulation under 3 different options:

Option A: $\mathrm{pH}$ adjusted down to 5.0 with $\mathrm{HCl}$ solution to use $\mathrm{FeCl} 3$

Option B: pH not adjusted but still using $\mathrm{FeCl}_{3}$

Option $\mathrm{C}$ : $\mathrm{pH}$ not adjusted, using $7 \mathrm{~g} / \mathrm{L}$ of $\mathrm{CaCO}_{3}$ as a coagulant

\section{Combination 2:}

1) Chemical coagulation under 2 options:

Option D: $\mathrm{pH}$ adjusted down to 5.0 to use $\mathrm{FeCl}_{3}$, then $\mathrm{pH}$ adjusted up to $\mathrm{pH} 11.0$ with $\mathrm{NaOH}$

Option E: pH adjusted using $7 \mathrm{~g} / \mathrm{L}$ of $\mathrm{CaCO}_{3}$

2) Air stripping for 48 hours, at an air flow of $1 \mathrm{~L} / \mathrm{L} / \mathrm{min}$

For all $\mathrm{pH}$ adjustments, a $25 \% \mathrm{w} / \mathrm{w}$ solution of sodium hydroxide $(\mathrm{NaOH})$ or a $18 \%$ w/w hydrochloric acid $(\mathrm{HCl})$ solution was used accordingly.

\section{RESULTS AND DISCUSSION}

\section{A. Air Stripping}

The overall ammonia removal rate was in the range of 24-95\% - Table II. The highest ammonia removal rate was achieved under the condition of $\mathrm{pH}$ value of 11 and 12 with no significant difference $(2 \%)$. Due to the consideration of chemical cost associated with increasing $\mathrm{pH}, \mathrm{pH} 11$ was selected as the optimal $\mathrm{pH}$ condition for this treatment. One interesting observation was that for all the tests with $\mathrm{pH}$ adjustment aeration did not improve the ammonia removal efficiency significantly as expected. On contrast, at $\mathrm{pH} 11$ and 12 , reactors without aeration showed slightly better ammonia removal rate. This suggested that $\mathrm{pH}$ is the key factor controlling the efficiency of ammonia removal. At high $\mathrm{pH}$ (> 10) majority of ammonia is in the gas form and mechanical mixing is sufficient for assisting ammonia evaporate from leachate. This observation is important for the real practice as the cost associated with aeration can be expensive.

During this test, it was observed that a thick foam layer was formed over the leachate surface while airflow was applied.
The foam layer usually overflowed the reactors during the first 30 minutes of the aeration process, then settled and formed a constant layer ( 5 to $20 \mathrm{~cm}$ ) over the surface area. This foam layer dissipated after the air was turned off in less than one minute. Foaming could present serious operation and maintenance issues in a full size application.

TABLE II: AMMONIA REMOVAL RATE AT DIFFERENT PH CONDITIONS

\begin{tabular}{|c|c|c|c|c|}
\hline $\mathrm{pH}$ value & 7 (original) & 10 & 11 & 12 \\
\hline Mixing, without aeration & $24 \%$ & $75 \%$ & $93 \%$ & $95 \%$ \\
\hline Mixing with aeration & $69 \%$ & $81 \%$ & $89 \%$ & $89 \%$ \\
\hline
\end{tabular}

The overall COD removal rate was quite low in the range of $0-7 \%$. The results showed that at same $\mathrm{pH}$ condition, aeration resulted in slightly higher COD removal than the treatment without aeration. This can be explained by the concept that aeration facilities the removal of volatile of organic compound in the leachate.

\section{B. Chemical Coagulation}

In this set of test, different dosages of coagulant $\mathrm{FeCl}_{3}$ $(100-650 \mathrm{mg} / \mathrm{L})$ as well as different $\mathrm{pH}$ conditions $(\mathrm{pH}$ value of 4, 5, 6 and 7.1) were investigated. The highest COD removal rate of $43 \%$ was obtained at $\mathrm{pH}$ of 5.0 with $\mathrm{FeCl}_{3}$ dosage of $500 \mathrm{mg} / \mathrm{L}(172 \mathrm{mg} \mathrm{Fe} / \mathrm{L})$. Tests carried out at the $\mathrm{pH}$ of 7.0 (leachate original $\mathrm{pH}$ ) and at 6.0 produced an average COD removal of only $10 \%$. When the $\mathrm{pH}$ is lowered from 5.0 to 4.0, COD removal also dropped from $43 \%$ down to $32 \%$. It was, therefore, concluded that $\mathrm{pH}$ of 5.0 with 500 $\mathrm{mg} / \mathrm{L}$ of $\mathrm{FeCl}_{3}$ was the optimal condition for this pretreatment option in terms of COD removal. Because coagulation targets particulate and ammonia in the leachate is in the dissolved form, therefore, ammonia removal rates from all the tests were insignificant in the range from 1-4\%. It was noticed that dosing $\mathrm{FeCl}_{3}$ resulted excellent TSS removal rate (76-99\%) in all the treatment condition. However, it also produced significant amount of sludge. This can be a drawback for the application of this technology.

\section{Electro-Coagulation}

The overall best results were provided by the highest current density (CD) tested $\left(300 \mathrm{~A} / \mathrm{m}^{2}\right)$ and the longest contact time (CT) of $30 \mathrm{~min}$. without any $\mathrm{pH}$ modification. Under these conditions, COD removal reached $18 \%$. The results for ammonia removal were fair low (average of $2 \%$ ).

Iron electrodes were used to produce the Ferric ions that acted as a coagulant. It was expected with the same amount of ferric ion produced under certain current density and time, the COD removal rate should be similar to the chemical coagulation. However, the results obtained from electro-coagulation were much lower than the chemical coagulation. At current density of $300 \mathrm{~A} / \mathrm{m}^{2}$ with 15 minutes, theoretically $261 \mathrm{mg} / \mathrm{L}$ of $\mathrm{Fe}^{3+}$ were produced. The test conducted under above condition with leachate $\mathrm{pH}$ adjustment to 6.0 the COD removal rate obtained was $1 \%$; while using $\mathrm{FeCl}_{3}$ as coagulant with the same operational condition, much higher COD removal rate of $10 \%$ was achieved. Compared to the COD removal results provided in related literature under comparable conditions (32\%, [13] and 
$90 \%$ [14]), and to the values obtained for chemical coagulation, the removal rates obtained from our test were much lower than expected.

These results confirm the complex nature of the treatment process and the numerous parameters that interact. A different electrode configuration (larger contact area, smaller gap between electrodes, larger number of electrode pairs) or different electrode materials could provide more positive results.

One of the most common problems associated with this process, is the formation of a scum layer on the electrodes, especially on the anode. The additional layer increases the resistance of the system which in turn demands more voltage to complete the circuit, resulting in higher electrical power consumption. The scum layer was observed during the experiments, but due to the relative short duration of the tests, no significant changes in resistance were measured.

\section{Advanced Oxidation with Sodium Ferrate}

Ferrate (VI) has been reported as a powerful oxidant and a coagulant. The highest COD and ammonia removal rates obtained from this treatment were $20 \%$ and $16 \%$, respectively These values were obtained under the condition of a $\mathrm{pH}$ of 5.0 and a dose of $200 \mathrm{mg} \mathrm{Fe} / \mathrm{L}$. Under the same operational condition, using $\mathrm{FeCl}_{3}(172 \mathrm{mg} \mathrm{Fe} / \mathrm{L})$ as coagulant provided a much higher COD removal rate of $43 \%$, but a lower ammonia removal rate of $5.7 \%$ (see chemical coagulation). In order to better understanding the oxidation of COD by ferrate, DOC was measured (shown in Fig. 1). As it can be seen that ferrate is very effective to remove DOC (approximately 64\%); however it is not as effective as $\mathrm{FeCl}_{3}$ in terms of removal of particulate COD presented in the leachate.

With comparison to chemical coagulation, the higher ammonia removal rate (16\% vs $5.7 \%$ ) can be explained by the oxidization of ammonia by Ferrate (VI) which is different mechanism of ammonia removal from coagulation.
The laboratory procedure followed to prepare the sodium ferrate stock solution was delicate and time consuming. Additionally, the solution must be prepared and used on the same day, as the ferrate compounds are unstable and can degrade in a matter of hours. This indicates that for the application of this particular treatment option, on site generation of the chemical would be required, along with the related operational costs.

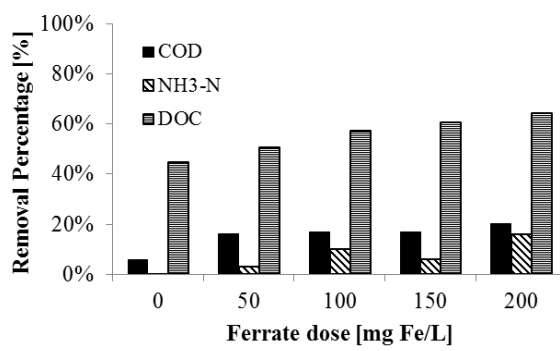

Fig. 1. Results of sodium ferrate pretreatment at $\mathrm{pH} 5.0$.

\section{E. Pretreatments Comparison}

Table III summarized the optimum operation condition for each pretreatment option.

Table IV presents the removal efficiency values obtained under the optimum conditions of each treatment option. The highest COD removal was obtained with chemical coagulation, while for ammonia removal air stripping was the best option.

\section{F. Biodegradability Observations}

BOD of the fresh leachate sample was measured at 248 $\mathrm{mg} / \mathrm{L}$ from a onetime sample. However, this value is consistent with the average of $245 \mathrm{mg} / \mathrm{L}$ reported by the landfill laboratory report. The BOD/COD ratio was used as a parameter to estimate "biodegradability" before and after each one of the pre-treatment methods - Table V.

TABLE III: OPTIMUM CONDITIONS FOR THE EVALUATED PRETREATMENT OPTIONS

\begin{tabular}{cccc}
\hline \hline Parameters & Air Stripping & Chemical Coagulation & $\begin{array}{c}\text { Sodium } \\
\text { ferrate }\end{array}$ \\
\hline $\mathrm{pH}$ & 11.0 & 5.0 & $\begin{array}{c}\text { Electro-coagulation } \\
\text { Conditions }\end{array}$ \\
\hline
\end{tabular}

TABLE IV: REMOVAL EFFICIENCY FOR THE ANALYZED PRETREATMENT OPTIONS

\begin{tabular}{lcccc}
\hline \hline Parameter & $\begin{array}{c}\text { Air } \\
\text { stripping }\end{array}$ & $\begin{array}{c}\text { Chemical } \\
\text { coagulation }\end{array}$ & Electro-coagulation & Sodium ferrate \\
\hline $\mathrm{COD}$ & $18 \%$ & $43 \%$ & $18 \%$ & $20 \%$ \\
$\mathrm{TSS}$ & $0 \%$ & $73 \%$ & $70 \%$ & $91 \%$ \\
$\mathrm{BOD} 5$ & $5 \%$ & $36 \%$ & $40 \%$ & $86 \%$ \\
$\mathrm{DOC}$ & $1 \%$ & $69 \%$ & $8 \%$ & $64 \%$ \\
$\mathrm{NH}_{3}-\mathrm{N}$ & $86 \%$ & $6 \%$ & $0 \%$ & $16 \%$ \\
$\mathrm{TP}$ & $22 \%$ & $75 \%$ & $74 \%$ & $61 \%$ \\
& & & & \\
\hline
\end{tabular}

TABLE V: BOD/COD RATIOS FOR UNTREATED AND TREATED LEACHATE

\begin{tabular}{cccccc}
\hline & Untreated & Air Stripping & Chemical Coagulation & Electro-coagulation & Sodium ferrate \\
\hline BOD/COD & 0.12 & 0.10 & 0.10 & 0.08 & 0.02 \\
\hline
\end{tabular}

The untreated leachate presents a BOD/COD ratio of 0.12 , which is considered as a low biodegradability. The four treatment options did not show any improvement in terms of increasing the BOD/COD ratio. Even more, for the last 2 
treatment options the $\mathrm{BOD} / \mathrm{COD}$ ratio decreased. Electro-coagulation and sodium ferrate had higher BOD removal compared to COD removal (40\% BOD removal versus $18 \%$ COD removal for electro-coagulation, for example). This shows that the last two treatment options were more efficient targeting and degrading biodegradable compounds. This would indicate that these options would yield better results applied to leachate with a higher BOD concentration.

\section{G. Combination of Selected Pretreatment}

Removal efficiency results for Combination 1 (Air stripping first, then chemical coagulation) are presented in Table VI. When the pH was directly modified at the start of the test (Column A) the removal efficiency presented the highest values. Not modifying the $\mathrm{pH}$ (Column B) or the substitution of ferric chloride for calcium carbonate (Column C) provided zero or little contribution.

TABLE VI: REMOVAL EFFICIENCY RESULTS FOR COMBINATION 1

\begin{tabular}{cccc}
\hline & \multicolumn{3}{c}{ Chemical coagulation } \\
\cline { 2 - 4 } Parameter & $\mathrm{pH} \Delta, \mathrm{FeCl}_{3}$ & $\mathrm{No} \mathrm{pH} \Delta, \mathrm{FeCl}_{3}$ & $\mathrm{No} \mathrm{pH}, \mathrm{CaCO}_{3}$ \\
& $(\mathrm{~A})$ & $(\mathrm{B})$ & $(\mathrm{C})$ \\
\hline \hline $\mathrm{COD}$ & $50 \%$ & $24 \%$ & $23 \%$ \\
$\mathrm{TSS}$ & $57 \%$ & $54 \%$ & $51 \%$ \\
$\mathrm{BOD}$ & $14 \%$ & $1 \%$ & $0 \%$ \\
$\mathrm{DOC}$ & $79 \%$ & $19 \%$ & $17 \%$ \\
$\mathrm{NH} \mathrm{H}_{3} \mathrm{~N}$ & $85 \%$ & $85 \%$ & $85 \%$ \\
$\mathrm{TP}$ & $76 \%$ & $67 \%$ & $68 \%$ \\
\hline
\end{tabular}

$\Delta=$ change (modification)

Combination 2 evaluated the results of treating leachate by chemical coagulation first, then air stripping (Table VII).

TABLE VII: REMOVAL EFFICIENCY RESULTS FOR COMBINATION 2 Parameter $\mathrm{pH} \Delta, \mathrm{FeCl}_{3} \quad \mathrm{No} \mathrm{pH} \Delta, \mathrm{CaCO}_{3}$

\begin{tabular}{ccc} 
COD & $45 \%$ & $10 \%$ \\
TSS & $0 \%$ & $30 \%$ \\
BOD $_{5}$ & $13 \%$ & $33 \%$ \\
DOC & $67 \%$ & $13 \%$ \\
$\mathrm{NH}_{3}-\mathrm{N}$ & $83 \%$ & $53 \%$ \\
$\mathrm{TP}$ & $74 \%$ & $47 \%$ \\
\hline
\end{tabular}

The results from this test showed that the order of the treatments (either starting with air stripping or with the chemical coagulation) had no significant impact on the result. Both processes provided similar pre-treatment results for the leachate, with COD and ammonia removal rate in the range of $45 \%$ to $50 \%$ and $83 \%$ to $85 \%$, respectively. Additionally, the substitution of ferric chloride for calcium carbonate (Columns
$\mathrm{C}$ and $\mathrm{E})$ proved to be less efficient.

\section{CONCLUSION}

Four methods of leachate pre-treatment were evaluated to determine the most efficient procedure in terms of COD and ammonia removal: air stripping, chemical coagulation, electro-coagulation and oxidation with sodium ferrate. Chemical coagulation provided the overall best COD removal rate at $43 \%$, while air stripping provided an ammonia removal rate of $86 \%$, superior to the results from the other pre-treatments for this compound. Chemical coagulation reduces COD by destabilizing the electric charges of colloidal particles and removing said particles by precipitation, co-precipitation (sweeping effect) and/or filtration. On the other hand, air stripping relies on the desorption of ammonia from the liquid by providing the right conditions $(\mathrm{pH}$, temperature, contact surface area, etc.) to favor the release of the gas.

The idea behind electro-coagulation was to provide the same iron salts (as chemical coagulation) without the additional compounds to minimize sludge production and costs. However, the delicate set of parameters needed to optimize the treatment to a specific leachate was not favorable. In the case of advanced oxidation with sodium ferrate, the compound was theorized to degrade recalcitrant compounds thus lowering the COD and providing a more biodegradable leachate. The long and complicated procedure to prepare and dose the right amount of sodium ferrate made the pre-treatment not efficient for the objectives of this research.

Pre-treating leachate with a combination of air stripping and chemical coagulation was shown to effectively reduce ammonia (83-85\% removal) and COD (45-50\% removal) from the leachate. The order in which the methods were applied did not affect the overall efficiency of the combined treatment

\section{REFERENCES}

[1] P. Kjeldsen, M. Barlaz, and A. Rooker, "Present and long-term composition of MSW landfill leachate: A review," Crit. Rev. Environ. Sci. \& Technol., vol. 32, pp. 297-336, 2002.

[2] T. A. Kurniawan, W. H. Lo, and G. Y. S. Chan, "Physico-chemical treatments for removal of recalcitrant contaminants from landfill leachate," J. Hazard. Mater., vol. 129, no. 1-3, pp. 80-100, 2006.

[3] S. Renou, J. G. Givaudan, S. Poulain, F. Dirassouyan, and P. Moulin, "Landfill leachate treatment: Review and opportunity," J. Hazard. Mater., vol. 150, no. 3, pp. 468-493, 2008.

[4] K. C. Cheung, L. M. Chu, and M. H. Wong, "Ammonia stripping as a pretreatment for landfill leachate," Water. Air. Soil Pollut., vol. 94, no. 1-2, pp. 209-221, 1997.

[5] C. Collivignarelli, G. Bertanza, M. Baldi, and F. Avezzu, "Ammonia stripping from MSW landfill leachate in bubble reactors: process modeling and optimization," Waste Manag. Res., vol. 16, no. 5, pp. 455-466, 1998 .

[6] M. Cotman and A. Z. Gotvajn, "Comparison of different physico-chemical methods for the removal of toxicants from landfil leachate," J. Hazard. Mater., vol. 178, no. 1-3, pp. 298-305, Jun. 2010 .

[7] G. Tchobanoglous, F. Burton, and D. Stensel, Wastewater Engineering, Treatment and Reuse, New York: McGraw-Hill, 2004.

[8] A. Amokrane, C. Comel, and J. Veron, "Landfill leachates pretreatment by coagulation-flocculation," Water Res., vol. 31, no. 11, pp. 2775-2782, 1997.

[9] E. Marañón, L. Castrillón, Y. Fernández-Nava, A. Fernández-Méndez, and A. Fernández-Sánchez, "Coagulation-flocculation as a 
pretreatment process at a landfill leachate nitrification-denitrification plant," J. Hazard. Mater., vol. 156, no. 1-3, pp. 538-544, 2008.

[10] A. Tatsi, A. Zouboulis, K. Matis, and P. Samaras, "Coagulation-flocculation pretreatment of sanitary landfill leachates," Chemosphere, vol. 53, no. 7, pp. 737-744, 2003.

[11] W. Li, T. Hua, Q. Zhou, S. Zhang, and F. Li, "Treatment of stabilized landfill leachate by the combined process of coagulation/flocculation and powder activated carbon adsorption," Desalination, vol. 264, pp. $56-62,2010$.

[12] M. Y. Mollah, P. Morkovsky, J. Gomes, G. Kesmez, M. Parga, and D. L. Cocke, "Fundamentals, present and future perspectives of electrocoagulation," J. Hazard. Mater., vol. 114, no. 1-3, pp. 199-210, 2004.

[13] F. Ilhan, U. Kurt, O. Apaydin, and M. Gonullu, "Treatment of leachate by electrocoagulation using aluminum and iron electrodes," J. Hazard. Mater., vol. 154, no. 1-3, pp. 381-389, 2008.

[14] S. Veli, T. Öztürk, and A. Dimoglo, "Treatment of municipal solid wastes leachate by means of chemical-and electro-coagulation," Sep. Purif. Technol., vol. 61, no. 1, pp. 82-88, 2008.

[15] J. Q. Jiang, "Research progress in the use of ferrate (VI) for the environmental remediation," J. Hazard. Mater., vol. 146, no. 3, pp. 617-623, 2007.

[16] Y. Lee, S. G. Zimmermann, A. T. Kieu, and U. V. Gunten, "Ferrate $(\mathrm{Fe}(\mathrm{VI}))$ application for Municipal wastewater treatment: A nove process for simultaneous micropollutantoxidation and phosphate removal," Environ. Sci. Technol., vol. 43, no. 10, pp. 3831-3838, 2009.

[17] D. Tiwari, J. K. Yang, and S. M. Lee, "Aplications of ferrate (VI) in the treatment of wastewaters," Environ. Eng. Res., vol. 10, no. 6, pp. 269-282, 2005.

[18] J. Q. Jiang, A. Panagoulopoulos, M. Bauer, and P. Pearce, "The application of potassium ferrate for sewage treatment," J. Environ. Manage., vol. 79, no. 2, pp. 215-220, 2006.

[19] ASTM Standard D2035, "Standard practice for coagulation-flocculation jar test of water," West Conshohocken, PA. ASTM International, 2013.
[20] J. Q. Jiang and B. Lloyd, "Progress in the development and use of ferrate(VI) salt as an oxidant and coagulant for water and wastewater," Water Res., vol. 36, no. 6, pp. 1397-1408, March 2002.

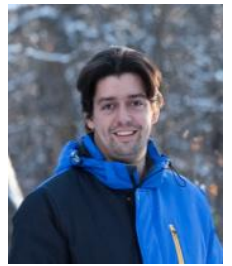

Mario Poveda was born in Costa Rica in 1983. He obtained his bachelor degree in civil engineering from the University of Costa Rica in 2008 and his master of science degree in civil engineering from the University of Manitoba, Canada, in 2015, with a focus on environmental engineering.

He worked as a project manager for a consulting company in Costa Rica for 4 years, in projects related to hydroelectric power plants, water and wastewater systems and solid waste management, taking part in the design of the largest landfill in Costa Rica to date. After finishing his post-graduate degree in Canada, he started working for a consulting company based in Manitoba. He is involved in the pre-design and design of wastewater treatment lagoons, solid waste disposal grounds and solid waste transfer stations in Saskatchewan, Manitoba and Ontario.

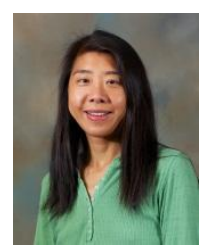

Qiuyan Yuan joined the Department of Civil Engineering, Faculty of Engineering, in July of 2013 as an assistant professor. She earned her Ph.D degree from the University of Manitoba. Her research interests are in the areas of biological nutrient removal from wastewater, solid waste treatment, and phosphorus recovery. The goal of her research is to develop sustainable technologies for water and waste treatment processes that will reduce the environmental burden, carbon footprint, and greenhouse gas emissions. Prior to joining the University of Manitoba as an assistant professor, she was a process specialist at Stantec Consulting Inc. where she worked on many process design projects for water and wastewater treatment plants. From these projects she gained valuable industrial experience which she continues to use in her research. She is also interested in community outreach to promote environmental awareness. 